\title{
Variation in the Essential Oils in Different Leaves of Basil (Ocimum basilicum L.) at Day Time
}

\author{
Xianmin Chang ${ }^{1, *}$, Peter G. Alderson ${ }^{2}$ and Charles J. Wright ${ }^{2}$ \\ ${ }^{1}$ Agronomy Institute, Orkney College UHI, East Road, Kirkwall, Orkney, KW15 1LX, UK and ${ }^{2}$ Division of Agricultural \\ and Environmental Sciences, School of Biosciences, The University of Nottingham, Sutton Bonington Campus, Lough- \\ borough, Leicestershire, LE12 5RD, UK
}

\begin{abstract}
Essential oil molecules released from fresh leaves of sweet basil (Ocimum basilicum L.) were collected in Tenax traps and analysed using a TD-GC/MS. During daytime from 09.00 to 17.00 , there were no differences in the content and composition of total essential oils, however the percentage of eugenol increased slightly. Significant differences were found in both the total content and composition of essential oils between young and mature leaves. The total content in young leaves was four times higher than in mature leaves, with fourfold, twofold and sixtyfold differences in the relative contents of linalool, eugenol and methyl eugenol respectively. There was no difference observed in the relative content of 1,8-cineole. The results therefore suggest that the defining sampling procedure is important when comparing the essential oils between treatments.
\end{abstract}

Key Word: Sweet basil, Ocimum basilicum, essential oil composition, linalool, eugenol, methyl eugenol, 1, 8-cineole.

\section{INTRODUCTION}

Sweet basil (Ocimum basilicum L.), a member of the Labiatae family, is a tender summer and herbaceous annual plant, 20 to $70 \mathrm{~cm}$ in height, which originates from tropical and warm areas, such as India, Africa and southern Asia. It is a popular herb, valued for its rich and spicy, mildly peppery flavour with a trace of mint and clove [1], and has been used widely as a food ingredient for flavouring confectionary, baked foods and meat products [2]. In Brazil, Ocimum species are used both in traditional medicine against bronchitis, coughs and sore throats, and in foods and flavourings [3].

Many different factors influence the quality and quantity of essential oil in basil, including leaf size and age [4]. In 1999, DeVasconcelos et al. [5] reported that there were significant differences during the daytime in the essential oil in Ocimum gratissimum leaves, however, the values reported were erratic, and no trend could be found.

This paper reports the analysis of basil leaves for any diurnal variation and effect of leaf age on total oil content and composition. It was hypothesized that essential oil content as well as composition would vary during the day due to changes in solar irradiance and temperature and that oil content would increase with increasing leaf age.

\section{MATERIALS AND METHODS}

Seeds of basil cv 'Basil Sweet Genovese' (NickersonZwaan Ltd, Lincolnshire, UK) were sown on the surface of

\footnotetext{
*Address correspondence to this author at the Agronomy Institute, Orkney College UHI, East Road, Kirkwall, Orkney, KW15 1LX, UK; Tel: 0044 1856 569294; Fax: 00441856569008 ;

E-mail: changxianmin2002@yahoo.co.uk
}

Levington F2s compost (Fisons Horticulture Ltd, Ipswich, UK) in plastic trays $(20 \times 30 \mathrm{~cm})$ in a glasshouse set at $21 \pm 3^{\circ} \mathrm{C}$. Seedlings with one pair of unfolded leaves were transplanted to $12 \mathrm{~cm}$ diameter plastic pots containing Levington M2A compost, and placed on benches. There was one plant per pot and grown on in the same glasshouse. Irradiance and temperature were recorded $50 \mathrm{~cm}$ above the benches with a Campbell CR10 data logger (Campbell Scientific, Inc. Logan, UT) at intervals of 60 min automatically.

This investigation was commenced in May 2002 and repeated in May 2003. Chemical analysis of leaf samples was carried out when plants had reached the six leaf-pair growth stage as the plants started to flower at seven leaf-pair growth stage.

For the study of diurnal variation, thirty six plants were placed on benches with four plants in a row and divided into three replicates. Two plants were randomly selected from the twelve plants of each replicate for sampling at each time. Leaf material $(5 \mathrm{~g})$ was harvested from the fifth pair of leaves of plants at $2 \mathrm{~h}$ intervals between 09.00 and 17.00. For the leaf age study, the field design was as the same as the design for the study of diurnal variation and carried out in the same glasshouse and the same time, however, samples were harvested at 10.00 from basal to top leaves and analyzed individually. For both studies, the fresh samples were immediately homogenized in an airtight blender and the volatile oils released were collected and analysed by TDGC/MS as described by Chang [6] and Chang et al. [7].

Chemical molecules were identified on the basis of relative retention times, using standard samples and comparing peaks with a library Wiley7n.L. Each analysis was performed in triplicate. The relative content of individual mole- 
cules was used to compare the composition of essential oils, and the sum of peak areas was used to compare the total oil content in the basil leaves.

Data for essential oil content and composition were subjected to analysis of variance (ANOVA) using GenStat. Differences between treatments were assessed using the F-test, and the Least Significant Difference (LSD) was calculated at the 0.05 probability level.

\section{RESULTS AND DISCUSSION}

\section{Study of Diurnal Variation}

The glasshouse temperature was relatively stable during this experiment with a mean of $21 \pm 2{ }^{\circ} \mathrm{C}$. Differences in total essential oil content measured throughout the daytime were not significant $(\mathrm{p}=0.928)$ (Fig. 1), notwithstanding the solar intensity ranging from 37.8 to 519.4 watts $/ \mathrm{m}^{2}$ (Table $\mathbf{1}$ ).

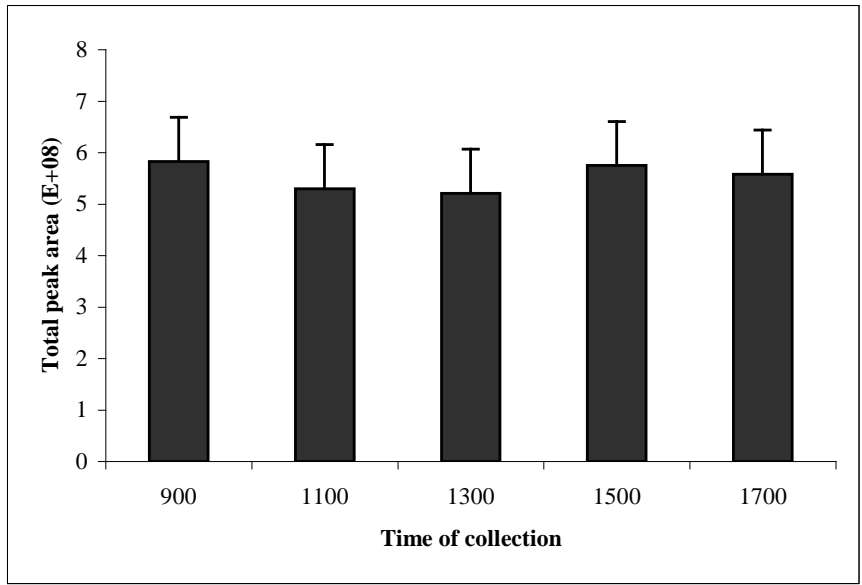

Fig. (1). Total essential oil content in basil leaves during the daytime.

Table 1. Temperature and Irradiance in Glasshouse on 9 May 2003

\begin{tabular}{|c|c|c|}
\hline Time of Recording & Temperature $\left({ }^{\mathbf{C}} \mathbf{C}\right)$ & Irradiance $\left(\right.$ watts $\left./ \mathbf{m}^{2}\right)$ \\
\hline \hline 07.00 & 21.0 & 37.81 \\
08.00 & 19.5 & 110.6 \\
09.00 & 19.5 & 247.9 \\
10.00 & 21.7 & 227.5 \\
11.00 & 23.0 & 195.3 \\
12.00 & 23.0 & 154 \\
13.00 & 22.7 & 179.2 \\
14.00 & 22.2 & 246.4 \\
15.00 & 22.4 & 260.4 \\
16.00 & 21.7 & 432.6 \\
17.00 & 22.1 & 519.4 \\
18.00 & 23.0 & 131.6 \\
\hline
\end{tabular}

Thirty-four chemical molecules were identified, but there were no differences in the composition, as illustrated by three main compounds, eugenol, 1,8-cineole and linalool (Fig. 2).

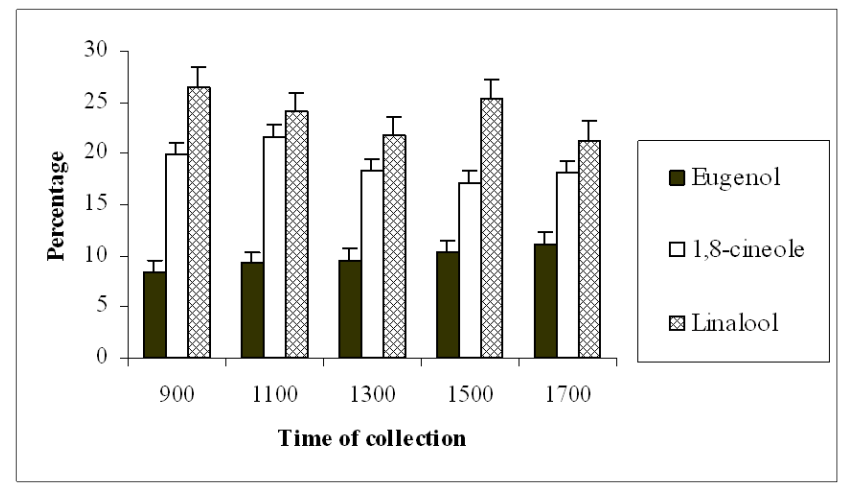

Fig. (2). The percentage of selected essential oil molecules in basil leaves during the daytime.

This contrasts with the findings of DeVasconcelos et al. [5] who reported variation during the daytime in the chemical constituents of the essential oil of Ocimum gratissimum leaves. They showed a considerable variation in the yield of eugenol, i.e. $98 \%$ at 12.00 to $11 \%$ at 17.00 , the opposite of the present results where eugenol was slightly, but not significantly, increased from 09.00 to 17.00. Unfortunately, their data were collected on only one day, there is no mention of replicates or the procedure used for sampling leaves and environmental conditions, i.e. temperature and irradiance, were not reported. In addition, the values reported were erratic, whereas a trend would have been expected. For the period 14.00 to 18.00 , the values (\%) for eugenol were 80.3, $27.5,67.0,11.4$ and 39.5 and for 1,8-cineole they were 0 , $60.7,32.5,75.5$ and 22.5. Such variation in the data could have been due to operator error, changes in irradiance due to cloud movements and lack of uniformity of sampling. It is also possible that a light dependent cultivar was used in the previous study because the composition of 1,8-cineole was $52.1 \%$ at 08.00 and $0.0 \%$ at 12.00 , and eugenol was $14 \%$ at 08.00 and $98 \%$ at 12.00 . This could be very relevant for crop breeding and production, however, it was not considered in that report.

\section{Study of Leaf Age}

Significant differences were found in the total content (Fig. 3) and composition (Table 2) of essential oils between the youngest and most mature leaves. There were no differences in the total content of essential oils between the second, third and fourth pairs of leaves, however differences between the fifth, sixth and folded leaves were significant. The folded leaves had a fourfold content compared to the second, third and fourth pairs of leaves. This supports the findings of Putievesky and Galambosi [4] that young leaves had a higher content of essential oil per unit area compared to old leaves, and that, as the leaf size increased, the essential oil content decreased which was contrary to our hypothesis.

There were thirty-four essential oil molecules identified in this study (Table 2), most of which did not differ significantly in the different leaves. However, there were significant differences in three main essential oil compounds, i.e. 
Table 2. Essential oil Molecules Identified in Basil Leaf Extracts and their Composition between Pair of Leaves from the Basal (2nd) to the Top Pair (Folded)

\begin{tabular}{|c|c|c|c|c|c|c|c|c|}
\hline \multirow{2}{*}{ Chemical } & \multicolumn{6}{|c|}{ Percentage $(\%)$} & \multirow{2}{*}{ SED } & \multirow{2}{*}{$\mathbf{P}$} \\
\hline & 2nd & 3rd & 4th & 5th & 6th & Folded & & \\
\hline$\alpha$-pinene & 1.48 & 1.45 & 1.55 & 1.54 & 1.55 & 1.12 & 0.420 & 0.909 \\
\hline$\beta$-pinene & 2.46 & 2.44 & 2.65 & 2.62 & 2.64 & 2.00 & 0.692 & 0.941 \\
\hline Myrcene & 1.69 & 2.33 & 2.58 & 2.67 & 3.02 & 2.57 & 0.507 & 0.299 \\
\hline$\alpha$-phellandrene & 0.25 & 0.29 & 0.28 & 0.27 & 0.31 & 0.21 & 0.050 & 0.601 \\
\hline 1,8-cineole & 22.20 & 22.40 & 22.10 & 22.00 & 19.10 & 21.80 & 4.150 & 0.959 \\
\hline Cis-ocimene & 2.92 & 4.33 & 4.48 & 4.07 & 5.16 & 3.15 & 0.097 & 0.297 \\
\hline$\gamma$-terpinene & 0.18 & 0.16 & 0.16 & 0.18 & 0.15 & 0.15 & 0.024 & 0.680 \\
\hline$\alpha$-terpinolene & 1.39 & 1.26 & 1.15 & 1.07 & 1.30 & 0.90 & 0.232 & 0.513 \\
\hline Linalool & 6.25 & 11.05 & 17.53 & 21.24 & 21.45 & 24.01 & 3.334 & 0.005 \\
\hline Camphor & 2.25 & 1.97 & 1.85 & 2.05 & 1.76 & 1.29 & 0.559 & 0.710 \\
\hline$\alpha$-terpineol & 0.36 & 0.33 & 0.30 & 0.29 & 0.31 & 0.49 & 0.053 & 0.500 \\
\hline$\alpha$-cis-bergamotene & 0.18 & 0.23 & 0.16 & 0.10 & 0.17 & 0.21 & 0.066 & 0.456 \\
\hline Trans-caryophyllene & 0.22 & 0.23 & 0.16 & 0.19 & 0.25 & 0.21 & 0.065 & 0.813 \\
\hline Trans- $\alpha$-bergamotene & 9.10 & 8.60 & 8.80 & 6.70 & 8.30 & 8.90 & 3.930 & 0.971 \\
\hline$\alpha$-guainene & 0.37 & 0.51 & 0.55 & 0.48 & 1.05 & 0.97 & 0.204 & 0.043 \\
\hline Trans- $\beta$-farnesene & 3.27 & 2.69 & 2.29 & 2.01 & 2.31 & 1.57 & 0.468 & 0.106 \\
\hline$\alpha$-humulene & 0.75 & 0.66 & 0.56 & 0.59 & 0.74 & 0.57 & 0.156 & 0.735 \\
\hline Germacrene-D & 1.53 & 1.55 & 1.94 & 2.26 & 2.73 & 2.61 & 0.490 & 0.166 \\
\hline$\beta$-selinene & 0.18 & 0.22 & 0.24 & 0.33 & 0.44 & 0.46 & 0.116 & 0.205 \\
\hline Germacrene-B & 0.61 & 0.75 & 1.01 & 1.39 & 1.80 & 1.50 & 0.474 & 0.204 \\
\hline$\beta$-bisabolene & 1.02 & 1.18 & 1.20 & 1.29 & 1.65 & 1.49 & 0.252 & 0.256 \\
\hline$\gamma$-cadinene & 0.89 & 0.96 & 1.26 & 1.58 & 2.04 & 1.96 & 0.411 & 0.101 \\
\hline$\beta$-sesquiphellandrene & 0.54 & 0.53 & 0.58 & 0.58 & 0.72 & 0.75 & 0.139 & 0.552 \\
\hline Total $(\%)$ & 93.20 & 92.47 & 94.18 & 94.18 & 95.75 & 96.73 & & \\
\hline
\end{tabular}




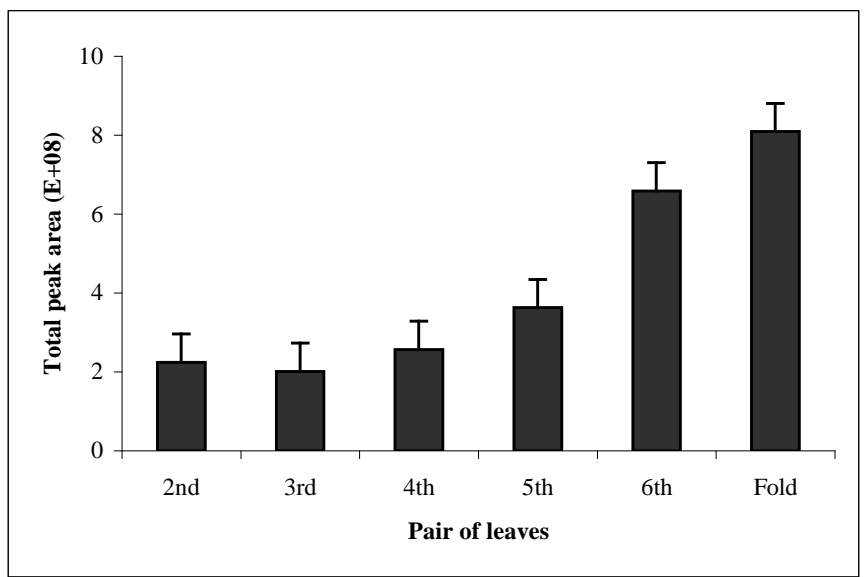

Fig. (3). Total content of essential oils in different pairs of leaves in basil.

linalool, eugenol and methyl eugenol, as well as in three others, i.e. fenchyl acetate, $\beta$-elemene and $\alpha$-guainene. There was no difference in another main essential oil, 1,8-cineole (Table 2). It was clear that the oil in the young leaves was rich in linalool and eugenol, while methyl eugenol was higher in the older leaves. This supports a previous report that there was a higher content of linalool in young leaves [8]. Catalysed by linalool synthase, linalool is synthesized from geranyl pyrophosphate (GPP) [9], which can also be catalysed by 1,8 -cineole synthase to form 1,8 -cineole $[9,10]$. In the current study, there was no difference in the relative contents of 1,8-cineole between young and mature leaves but a significant difference was found for linalool, suggesting that further research should be aimed at determining how the enzymes work, thereby regulating the relative content of linalool.

Eugenol is the precursor of methyl eugenol [10]. It was assumed that eugenol was synthesized in the young leaves and that some of it was methylated to methyl eugenol as the plant grew and leaves became older, This needs further investigation. According to a previous report on the biosynthesis of phenylpropenes in basil, eugenol $O$-methyltransferase (EOMT) is the enzyme that controls this synthesis [10].

\section{CONCLUSIONS}

During the daytime from 09.00 to 17.00 , there were no differences in the total content and composition of essential oils in fresh basil leaves although the percentage of eugenol increased slightly. It can be considered that the original hypothesis was not correct. Significant differences were found in the content and composition of essential oils between young and mature leaves, which highlights the importance of defining sampling procedures when comparing the essential oils between treatments.

\section{ACKNOWLEDGEMENTS}

The senior author gratefully acknowledges the financial assistance provided by the Division of Agricultural and Environmental Sciences, the University of Nottingham.

\section{REFERENCES}

[1] Xie F, Hu Y. A Colour Atlas of Traditional Chinese Medicines with Text on Techniques of Their Cultivation. JinDun Press: China $1995 ;$ p. 377.

[2] Wan J, Wilcock A, Coventry MJ. The effect of essential oils of basil on the growth of Aeromonas hydrophila and Pseudomonas fluorescens. J App Microbiol 1998; 84: 152-8.

[3] Vieira RF, Simon JE. Chemical characterization of basil (Ocimum spp) found in the markets and used in traditional medicine in Brazil. Econ Bot 2000; 54: 207-16.

[4] Putievsky E, Galambosi B. Production systems of basils. In: Hiltunen R, Holm Y, Eds. Basil: The Genus Ocimum. Harwood Academic Publishers: 1999; pp. 39-65.

[5] DeVasconcelos SMG, Craveiro AA, Abreu Matos FJ, Machado MIL, Alencar JW. Chemical variation during daytime of constituents of the essential oil of Ocimum gratissimum leaves. Fitoterapia 1999; 70: 32-4.

[6] Chang X. Effects of Light and Temperature on Volatile oil Compounds and Growth in Basil (Ocimum basilicum L.). PhD Thesis, University of Nottingham, UK 2004

[7] Chang X, Alderson PG, Wright CJ. Effect of temperature of integration on the growth and volatile oil content of basil (Ocimum Basilicum L.). J Hortic Sci Biotechnol 2005; 80: 593-8.

[8] Werker E, Putievsky E, Ravid U, Dudai N, Katzir I. Glandular hairs and essential oil in developing leaves of Ocimum basilicum L. (Lamiaceae). Ann Bot 1993; 71: 43-50.

[9] Kaufman PB, Cseke LJ, Warber S, Duke JA, Briemann HL. Natural products from plants. CRC Press. Boca Raton, FL, USA 1998.

[10] Gang DG, Wang J, Dudareva N, et al. An investigation of the storage and biosynthesis of phenylpropenes in sweet basil. Plant Physiol 2001; 125: 539-55. 